\title{
Kentsel Kimlik Bileşenlerinin Kent Kullanıcıları Tarafından Belirlenmesi: Örnek Kent Çanakkale
}

\author{
Elif Sağl1k ${ }^{1^{*}}$, Abdullah Kelkit ${ }^{2}$ \\ ${ }^{1}$ Çanakkale Onsekiz Mart Üniversitesi, Lapseki Meslek Yüksekokulu, Park ve Bahçe Bitkileri Bölümü \\ ${ }^{2}$ Çanakkale Onsekiz Mart Üniversitesi, Mimarlık ve Tasarım Fakültesi, Peyzaj Mimarlığı Bölümü \\ 13.03.2019 Geliş/Received, 03.05.2019 Kabul/Accepted
}

\section{Özet}

Kentlerin sahip oldukları tüm değerler o kentin kimliğini oluşturmaktadır. Kentsel kimlik bileşenlerinin tespit edilmesinde en uygun yaklaşım kent kullanıcılarının kente yaptıkları atıflardır. Kente yapılan atıflara ulaşmak için kent kullanıcıları ile yapılan görüşmeler önemli bir araçtır. Bu amaç doğrultusunda; çalışma materyali olarak Çanakkale kenti ve kullanıcıları seçilmiştir. Çalışma, yazılı kaynak araştırması ve anket uygulaması yöntemi ile Çanakkale kent merkezi sınırları içerisinde örneklenmektedir. Çalışmanın teorik yaklaşımını oluşturan kentsel kimlik tipi ve bileşen kavramları anket formlarının oluşturulmasında belirleyici olmuştur. Kullanıcıların kent için imgesel değerlendirmelerini yapmak amaciyla \%0.05 örneklem hacmini yansıtan, rastgele örnekleme tekniği ile toplam 112 anket uygulaması yapılmıştır. Anket formu, Çanakkale kent ölçeğinde halkın sosyo-demografik yapısı ile ilgili verilere ve çalışma alanına özel yerleşim, donatı ve işaretler ölçeğindeki kimlik bileşenlerine ulaşmayı sağlayacak olan detaylı soruları içermektedir. Değerlendirmeler sonucunda Çanakkale kenti için ortaya çıkan tarih, turizm ve boğaz kavramlarının birlikte oluşturduğu kompozisyon ile kentin kavramsal yapısı ortaya konmuştur. Fiziksel yapı bileşenleri ise; yollar (Atatürk Caddesi), odak noktaları (Cumhuriyet Meydanı), kentsel donatılar ve işaretler (Rüzgar Gülleri ve Saat Kulesi) ve kentsel sınır (Sarıçay) ölçeğinde belirlenmiştir. Kentin yerel yönetim boyutunda pratik fayda sağlaması beklenen bu çalışmanın sonucunda Çanakkale'ye ilişkin kentsel kimlik kartı düzenlenmiştir.

Anahtar Kelimeler: kent, kentsel kimlik, Çanakkale

\section{Determination of Urban Identity Components by City Dwellers: Çanakkale City Case Study}

\begin{abstract}
All the values that a city possesses constitute the urban identity of that city. The most appropriate approach in determining the urban identity components is the references that the city-dwellers make for the city. Interviews with city-dwellers are an important tool for obtaining these references. In accordance with this purpose; city of Çanakkale and its dwellers were selected as study material. The study is sampled within the borders of Çanakkale city center with written source research and survey application method. Urban identity type and

*Sorumlu Yazar (Corresponding Author): Elif Sağlık

(e-posta:elifsaglik@comu.edu.tr)

Bu makale Prof. Dr. Abdullah Kelkit danışmanlığında, Elif Sağlık tarafından yapılan doktora tezi kapsamında yazılmıştır.
\end{abstract}


component concepts that constitute the theoretical approach of the study have been determinant in preparing the questionnaire forms. A total of 112 questionnaires were applied by random sampling technique, which reflects the sample volume of $0.05 \%$, for enabling the dwellers to make imaginary evaluation of the city. The questionnaire contains detailed questions that will provide access to data on the socio-demographic structure of the community and the identity components of settlement, equipment and signs specific to the study area. As a result of the evaluations, the conceptual structure of the city was revealed with the composition of history, tourism and strait concepts that emerged for the city of Çanakkale. Physical structure components were determined on the scale of roads (Atatürk Street), focal points (Republic Square), urban equipment and signs (Wind Roses and Clock Tower) and urban boundary (Sarıçay). As a result of this study, which is expected to provide practical benefit in the local government dimension, an urban identity card was issued in regard to Çanakkale.

Keywords: urban, urban identity, Çanakkale

\section{Giriş}

Son yıllarda yaşanan sosyo-ekonomik ve teknolojik gelişmeler kentin her boyutunda değişimlere neden olmaktadır. Yaşanan değişimler kentlerin günlügüne kent dokusu ve yapısını etkileyen olumsuz durumlar olarak yansıtmaktadır. Kentin dokusu ve yapısında görülen değişimler, kent bilimi ile ilgilenen uzmanları kentlerin kendisini ve kimliğini sorgulamaya yöneltmiştir. Değişimlerin doğrudan etkilediği kent dokusu ve yapısı kentin kimliğini oluşturan bileşenlerdir. Kimlik bileşenleri her kent için değişkendir.

Kimlik, bir şeyi diğerinden farklı kılan, ayıran özelliktir (Anonim, 2018a). Kimlik "Toplumsal bir varlık olarak insanın nasıl bir kimse olduğunu gösteren belirti, nitelik ve özelliklerin bütünü; kişinin kim olduğunu tanıtan belge, kimlik belgesi, tanıtma kartı, hüviyet; herhangi bir nesneyi belirlemeye yarayan özelliklerin bütünü” olarak tanımlanmaktadır (TDK, 2018).

Geniş bir çalışma konusu olan kimlik bir yer için tanımlandığında ise; o yeri diğerlerinden ayıran, farklı kılan karakter ve üstünlüklerin oluşturduğu özelliklerdir (Pazhuhan ve ark., 2015). Kent kimliği, günün her bölümünde yer alan ve dolaylı olarak kenti kullanan kişilerin kent için oluşturduğu algıda ortaya çıkmaktadır (Zhou ve ark., 2014). Kent kimliği; nesnel ya da öznel bir kavram olmaktan öte kentlerin sürdürülebilir olması için yapılan çalışmalarda en önemli konudur. Aynı zamanda kimlik kent ruhunu ve toplumsal algıyı kapsayan dinamik bir kavramdır (Tavakoli, 2010).

Kentsel kimlik; bir kent için bazen bir obje, anıtsal değer ya da karakteristik özellikler ile tanımlanmaktadır. Örneğin Londra kentinde Big Ben-Westminster, Paris'te Eiffel Tower, Sydney kentinde ise Sydney Opera binası kentsel kimlik tanımlayıcısı niteliğindedir (Mansour, 2015).

Her kentin kimliğinde, kentin süreklilik kazanmış olan ayırt edici özelliklerin bulunduğunu savunan Amerikan Şehir Plancısı Kevin Lynch, kimliği bir nesnenin diğer nesnelerden farklı, tek ve eşsiz olması, hiçbir şeye eşit olmaması olarak tanımlamaktadır. Lynch (2015), kentsel imge öğelerini; bölgeler (districts), yollar (paths), dügüm noktaları (nodes), kenarlar (edges) ve nirengi noktaları (landmarks) olarak sinıflandırmaktadır (Şekil 1.1). Kent dokusunun karmaşık bir yapı olduğunu ve üzerinde çalışma yapılabilmesi için kentin görselleştirilmesi 
gerektiğini vurgulamaktadır. Kent imgesi kuramına göre, kentsel çevre beş ana elemandan yola çıkılarak görselleştirilmektedir.

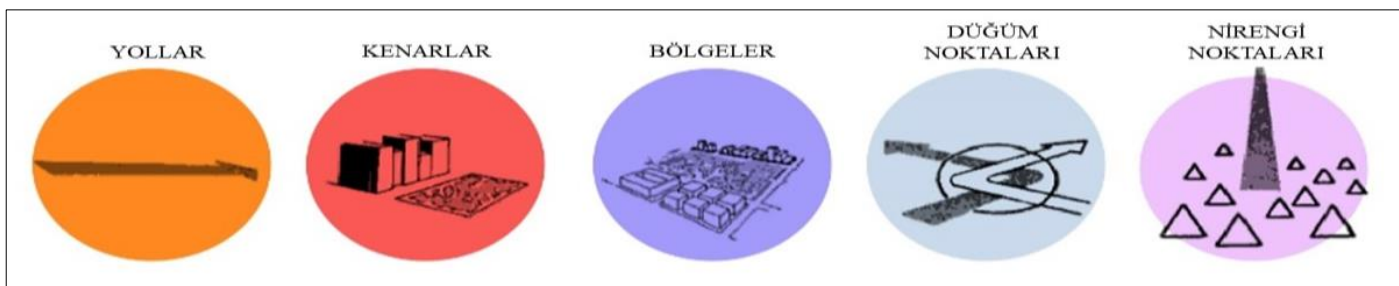

Şekil 1.1. Kentsel dokuyu oluşturan imge öğeleri (Google Images-Architecture of the City)

Bir kentte yaşayanların hafizasında yer alan benzersiz imajlardan oluşan konsept, o kentin kimliğine yansımaktadır (Rıza ve ark., 2012). Bu nedenle kent kimliği o kent için tekrar üretilemeyen ancak sürekliliği sağlanabilen özel bir olgudur.

Lynch (2015) "Kent İmgesi" adlı çalışmasında, kenti temel olarak 5 görsel algılama birimine bölmüştür ve insanların kafasında kentlerin belleksel bir harita şeklinde bulunduğunu ve insanların bu sadeleştirmelerle kentte yolunu bulduğunu ifade etmektedir. Temel olarak 5 görsel algilama birimleri ise;

1. Yol: sokaklar, kaldırımlar, patikalar, doğrultular, insanların üzerinde gittiği her kanal,

2. Kenar: duvarlar, bina kenarları, kıyılar gibi algılanan sınırlar,

3. Bölge: belli bir ortak karaktere sahip büyükçe alanlar,

4. Düğüm noktası: merkezi noktalar, meydanlar, kavşaklar,

5. Anıt: bölgedeki diğer her şeyden farklı, kolayca algılanabilen ve bir referans noktası oluşturabilecek objelerdir.

Kent kimliği geniş bir kavram olması nedeniyle farklı türlere ayrılabilmektedir. Kent kimliği; fiziksel kimlik, sosyal kimlik, kültürel kimlik, tarihsel kimlik, biçimsel kimlik ve kent işlevlerinin ortaya koyduğu kimlik olarak çeşitlilik göstermektedir. Bugün kent kimliğinden daha çok, kent işlevlerinin ortaya koyduğu kimlik olarak söz edilmektedir. Ancak bu sadece kent kimliğinin bir türünü ifade etmektedir (Özgür, 2011).

Kentsel kimlik, bir kentin veya çevrenin doğal, yapay elemanları ve sosyo-kültürel özellikleriyle tanımlanır. Bu özelliklerin içinden belirgin ve etkileyici olabilenler, o kentin kimliğini oluşturmaktadır (Oğurlu, 2014). Tüm bu araştırmalardan yola çıkılarak bir kentin kimliğinin, karakterinin; kentin doğal, sosyo-kültürel, sosyo-ekonomik ve yapılaşmış çevresinin mekânsal öğeleri ile bir bütün olarak değerlendirilmesinin gerekliliği ortadadır. Bu nedenle, Şekil 1.2'de gösterildiği gibi kent kimliği bileşenleri, çalışma kapsamında yapılan literatür araştırması sonucunda aşağıdaki gibi sınıflandırılmıştır (Topçu, 2011). 


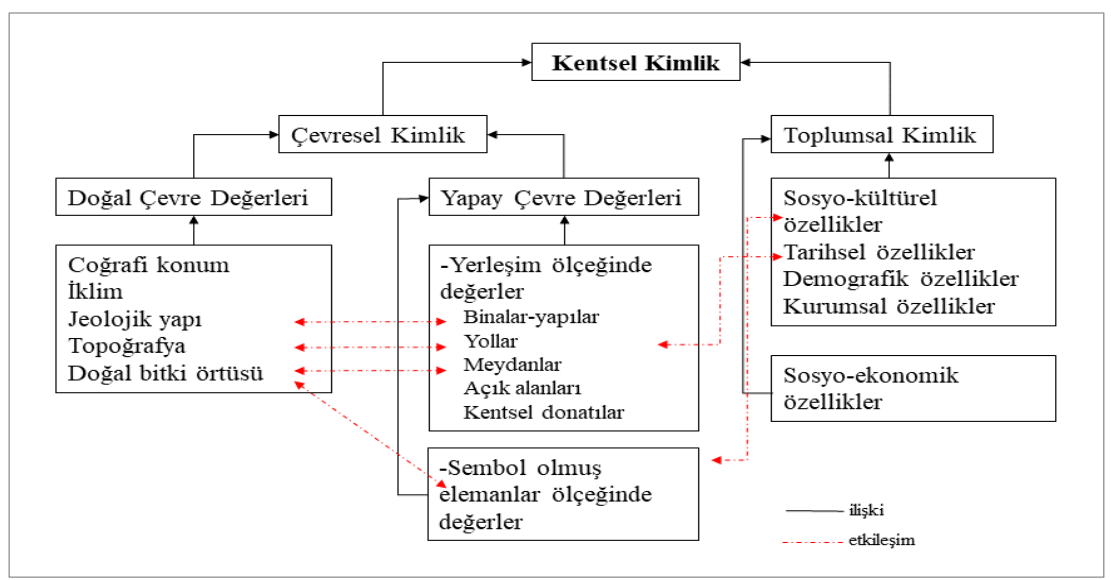

Şekil 1.2. Kentsel kimlik bileşenleri (Topçu, 2011)

Kentsel kimlik elemanı olarak değerlendirilen bu bileşenler, farklı kentlerde farklı değerler olarak ön plana çıkabilmektedir. Gelibolu Yarımadası'nın savaşla kazanmış olduğu anlam, İstanbul'un coğrafyası ve doğal değerleri, Şanlıurfa'nın iklimsel özellikleri gibi değerler ve kentin biçimlenmesinde ağırlıklı olan öğeler bu farklılığa örnek olarak gösterilebilir (Uçkaç, 2006).

Kentsel kimlik, toplumların yaşam biçimlerinin ve çevreyle etkileşim düzenlerinin fiziksel mekâna yansıma göstergesidir. Kentsel kimlik aslında kentin sahip olduklarının, kullanıcılar tarafından nasıl algılandığının da bir sonucudur. Kent hangi mimari ve işlevsel donanımlara sahip olursa olsun, insanların algısı, kentsel kimliğin en önemli belirleyicilerinden biridir. Her kentin kendine özgü bir tarzı, dokusu, fiziksel ve sosyal yapısı bulunmaktadır. Bu durum kent kimliğginin oluşum nedenlerini ortaya çıkarmıştır. Her kent ya da yerleşim bölgesi için ortaya çıkan belirli farklılıklar ve değişkenler kent kimliğinin oluşumunu sağlamıştır (Çöl, 1998).

"Bir kentte hayran kaldığın şey onun yedi ya da yetmiş harikası değil, senin ona sorduğun bir soruya verdiği yanıttır" (Calvino, 1972) yaklaşımı kent kimliğinde kullanıcının atıfının önemli olduğunu göstermektedir. Bu kapsamda kentin "ne" olduğu kadar, "nasıl" algılandığı o kentin kimliği açısından son derece önemlidir. Yapılan çalışmanın amacı, kent kimliğinin ve bileşenlerinin kent kullanıcıları tarafından belirlenmesidir. Bu amaç doğrultusunda geçmişten günümüze Çanakkale için önemli bir kentsel bölge olan kent merkezinin nasıl algılandığı, kimliğinin ne olduğu sorgulanmıştır. Çalışma amacı bağlamında; Çanakkale kent merkezinin beşeri, doğal ve yapay çevreden kaynaklı kimlik bileşenleri analiz edilmiştir. Analizlerde kent kullanıcılarına yönelik yapılan anketlerden elde edilen bilgilerle kentsel kimlik bileşenleri saptanmıştır.

\section{Materyal ve Yöntem}

\subsection{Materyal}

Çalışmanın birincil materyalini Çanakkale kent merkezi oluşturmaktadır. Konu, kapsam ve alana yönelik yapılan literatür çalışmalarından elde edilen veriler ile anket formları ikincil materyal olarak kullanılmıştır. Kentsel kimlik kavramını anlamak ve yorumlamak için örneklem alanı olarak Çanakkale kent merkezi seçilmiştir (Şekil 2.1). Bu seçimin yapılmasında,

- Çanakkale kentinin en önemli kentsel bölgesini oluşturması, 
- Kentin tarihi açıdan ilk yerleşim bölgesi olması,

- Merkez ilçe olma özelliği,

- Çanakkale kimliği açısından önemi,

- Çanakkale kentinde gerçekleşen değişimlerin büyük bölümünün bu ilçede olması,

- Kıyı ile bütünleşen yapıda olması,

- Önemli ticaret ve hizmet alanlarının bulunması,

- Doğal ve kültürel özellikler ile kültür, sanat ve spor etkinlikleri ile dinamik bir ilçe olmas1,

- Pek çok döneme ait eserin bu alanda bulunması etkili olmuştur.

Çanakkale, tüm ülkelere ilham vermiş olan bir destanın yaşandığ 1 yer olan Troya Antik Kenti nedeniyle dünya sahnesinde bilinirliği olan kenttir. Bu nedenle tarihi ve kültürel yönü güçlü olup coğrafi özellikleri ve konumu itibariyle ülkemiz ve dünya açısından önem taşıyan bir kenttir.

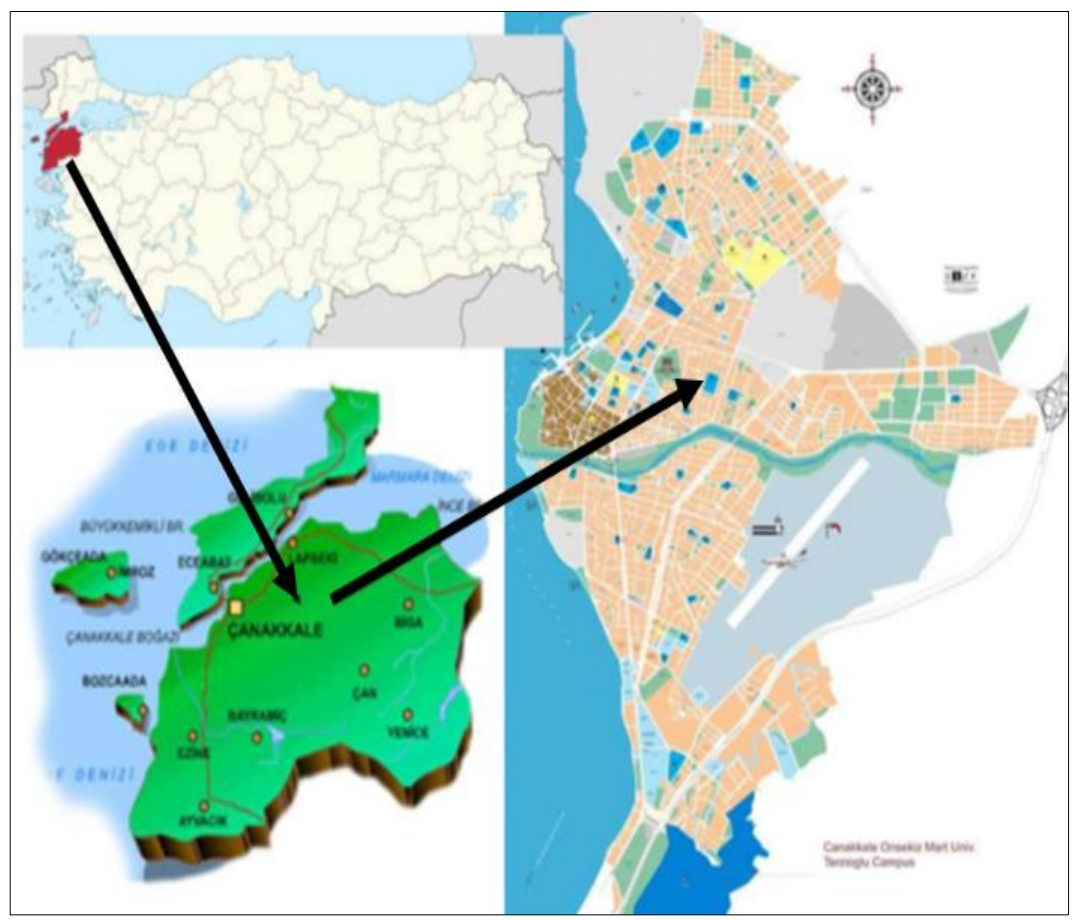

Şekil 2.1. Çalışma alanının ülke ve Çanakkale içindeki konumu (Google Haritalar'dan değiştirilerek)

Çalışma alanı; Çanakkale kentinin en önemli kentsel bölgesini oluşturan ve bir çok kentsel bileşeni bulunduran kent merkezidir. Çalışma alanı sınırları; Üniversite Kavşağı - Piri Reis Caddesi - D200 Karayolu - Bursa/İzmir karayolu aksları arasında kalan bölge olarak belirlenmiştir (Şekil 2.2). 


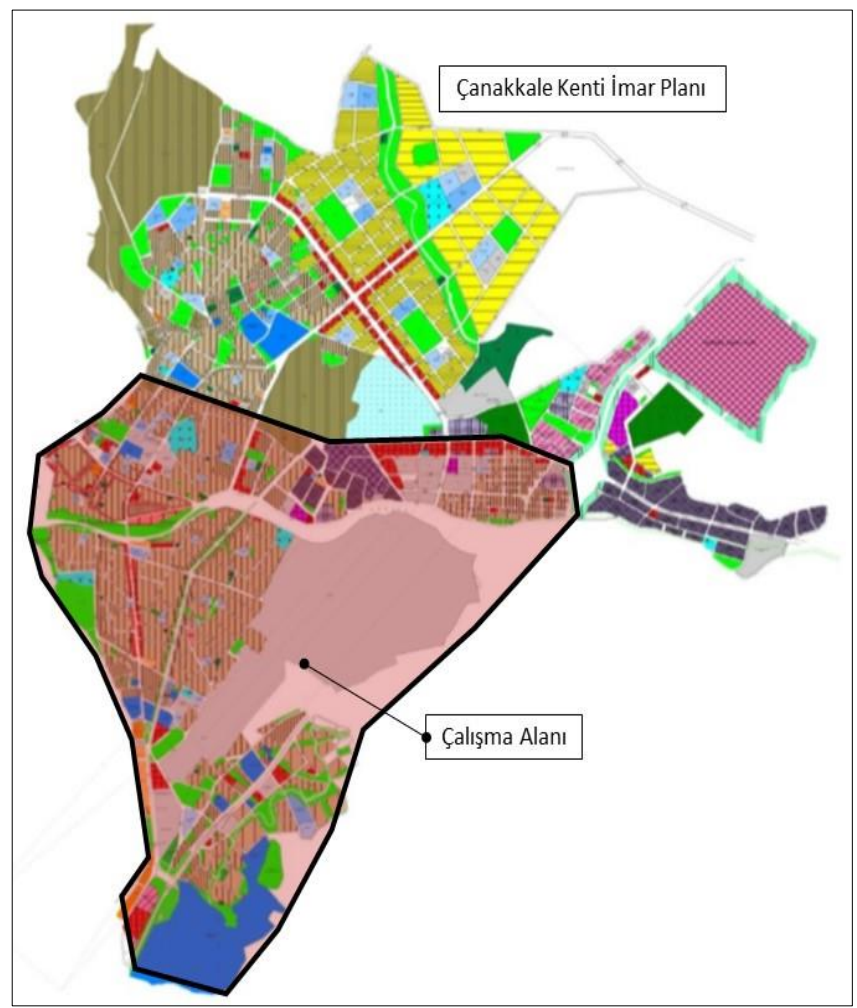

Şekil 2.2. Çanakkale kenti imar planı ve çalışma alanı

\subsection{Yöntem}

Çalışma yöntemi; "Konunun Tanımlanması", "Veri Toplama", "Bulgular ve Analiz" ile "Sonuç" olmak üzere dört aşamadan oluşmaktadır. "Konunun Tanımlanması" aşamasında konuya ilişkin kavramsal ve kuramsal araştırmalar yapılmıştır. Araştırmanın "Veri Toplama" aşamasında, kentsel kimlik bileşenlerinin saptanması amacıyla kullanıcı değerlendirmesine ulaşmayı sağlayan anket yönteminin kullanılmasına karar verilmiş olup çalışmaya yönelik yöntem belirlenmiştir.

Anket formlarının hazırlanmasında konuya ilişkin literatür çalışmalarından elde edilen bilgilere ek olarak Lynch (2015), Kodal (2014) çalışmaları yönlendirici olan kaynaklardır. Çalışmada, Çanakkale kentinde yaşayan kentlilere anketler yüz yüze yöntemi ile gerçekleştirilmiştir. Veri girişi aşamasında toplam 112 anket uygulama için kullanılmıştır. Çanakkale kent merkezinde 132.854 (TÜİK, 2018) kişi yaşamaktadır. Yani; anakütle 132.854 kişiden oluşmaktadır. Ankete katılmayı kabul eden Çanakkale kent kullanıcı sayısının robust (sağlam) sonuçlar üretebilme yeteneğini tespit edebilmek açısından Güç (power) analizi G*POWER 3.1 sürümüyle yapılmıştır. Çalışmalarda, istatistiksel gücün $1-\beta=0.95$ olmasının yeterli olduğu Cohen (1988) ve Parajapati ve ark. (2010)'nın yapmış oldukları çalışmalarda ortaya koyulmuş olup ilişkiler ve grup farklılığı hesaplanacağı belirtilerek sonuçlar elde edilmiştir. İstatistik anlamlılık düzeyi $\alpha=0.05$ olarak belirlenmiştir.

Anket uygulaması, 2018 yılı Nisan-Mayıs ayı tarihleri arasında yapılmış olup, toplamda 15 adet (sosyo-demografik profil, derecelendirme, sıralama ve açık uçlu sorular) soru sorulmuştur. Araştırmada uygulanan anket formlarında araştırma alanına yönelik algısal değerlendirmelerin ve görüşlerin sorgulandığı, imgesel sorgulamayı hedefleyen açık uçlu sorulara yer verilmiştir. Böylece anket formunun yönlendirici olmamasına özen gösterilmiştir. Anket formunda üç adet demografik özelliklerin sorgulandığı, 1 adet derecelendirme, 6 adet 
önem derecesi göre sıralama ve beş adet açık uçlu tipte olmak üzere toplam 15 adet soruya yer verilmiştir.

"Bulgular ve Analiz" bölümünde anket sorularına verilen cevaplar, IBM SPSS 22.0 (Statistical Packages For Social Sciences) programı aracılığıyla bilgisayar ortamına aktarılmış olup önem derecesine göre sıralamalar yapılmıştır. Çanakkale kenti için kullanıcının kente yönelik oluşturduğu imgeyi ölçmek üzere sunulan ifadeleri kabul etme dereceleri 5'li Likert tekniği ile saptanmasından oluşmaktadır. Anketin dördüncü kısmında ise; yol-engel-sınırmeydan-toplanma alanı- görsel-işitsel-koku gibi kentsel kimlik bileşenlerinin kullanıcılar tarafindan belirlenmesi istenmektedir. Anketin son kısmında; kent kullanıcılarının demografik yapısı ile Çanakkale'de bulunma sürelerine ilişsin sorulara yer verilmektedir.

Çalışmanın "Sonuç" bölümünde araştırma alanı olan Çanakkale kent merkezine yönelik kent kullanıcılarının imgesel algısında öne çıkan kimlik bileşenleri saptanmıştır.

\section{Bulgular}

\section{1. Çalışma Alanına İlişkin Bulgular}

Çanakkale kenti için bir tanımlama yapılırken, Türkiye ve dünya üzerindeki coğrafi konumunu dikkate almak gerekmektedir. Çanakkale; dünya üzerinde denizleri birbirine bağlayan önemli geçiş noktalarından birisi olan Çanakkale Boğazı'nın iki yakasında kurulmuş bir kenttir. Kent, kuruluşundan itibaren stratejik önem taşımış olup tarihi ve kültürel değerleri künyesinde bulundurmaktadır (Soydan, 1997). Mavi ile yeşilin buluştuğu bir coğrafyada odak nokta olan Çanakkale kenti Edirne, Tekirdağ ve Balıkesir illeriyle çevrilidir.

Türk ve dünya tarihinin en dramatik ve en anlamlı olaylarından birisini oluşturan 'Çanakkale Savaşları'nın Çanakkale topraklarında yaşanmış olması Çanakkale kentini diğer kentlerden ayıran en önemli özelliktir. Tarihin en yakın tanı̆̆ı olan Çanakkale, kolektif bellekte oluşturduğu güçlü etki ile diğer kentlerden ayrıcalıklı konumdadır.

Çanakkale'yi değerli kılan tüm özellikler bölgede sürekli olarak birçok medeniyete ait yerleşimler kurulmasına neden olmuştur (Tombul, 2015). Bu yerleşimler ile renkli bir kültür mozaiği ortaya çıkmıştır. Genç bir kent olan Çanakkale'de, ilgili kurum ve kuruluşlar tarafından organize edilen festivaller, bienaller, sanatsal faaliyetler düzenli olarak yapilmaktadır.

Dünyanın önemli kültürel miraslarından biri olan Troya Destanı kente evrensel bir değer katmaktadır. UNESCO; Troya'nın Dünya Kültür Mirası Listesine kabul edilmesinin 20. yılı olması nedeniyle tüm dünyada 2018 Troya Yılı'nı ilan etmiştir. Bu kapsamda; yapılan çalışmanın, kentte yapılan etkinliklerin bilimsel basamağında önem taşıyacağı düşünülmektedir.

\section{2. Çanakkale Kent Merkezi Tarihi}

Çanakkale kent merkezi, geçiş noktasında olması nedeniyle güvenlik bakımından yetersiz durumdadır. $\mathrm{Bu}$ sebeple ege denizinden gelebilecek her türlü tehlikeye karşı boğazın iki yakasında kale inşa ettirilmiştir (Koç, 2006). Boğaz'ın Asya yakasında 1462-1463 yılında inşa ettirilen kaleye Kala-i Sultaniye, Avrupa yakasında yapılan kaleye Kilid-ül Bahir adı verilmiştir. Kala-i Sultaniye'nin inşa edildiği tarihte bu bölgede bir yerleşim mevcut olmayıp 
en yakın yerleşme, kentin kuzeyinde gelişim göstermiştir. Osmanlı'nın son döneminde Kala-i Sultaniye ismiyle birlikte, kalenin çanağa benzemesinden dolayı halk tarafından verilen Çanakkale adı kullanılmaya başlanmıştır (Anonim, 2018b).

Savunma amaçlı kurulan kent ve bu amaç doğrultusunda yapılan kalelerin bulunduğu alanların yakın çevresinde ilk yerleşim bölgeleri gelişim göstermiştir. Günümüzde kentin dokusunda önemli olan bu bölgeler Fevzipaşa Mahallesi ve yakın çevresi olarak tanımlanmaktadır.

\section{3. Çanakkale Kentinin Mekânsal Olușum Süreci}

Çanakkale'de özellikle son yıllarda hareketli bir yapılaşma ve kentleşme hızı gözlenmektedir. Çanakkale kenti Türkiye'nin kuzeybatısında, Marmara Bölgesinin güneybatısında, Çanakkale Boğazı'nın en dar yerinde konumlanmıştır (Anonim, 2014). Bu konum kenti biçimlendiren en önemli etkendir. Çanakkale kentinin yerleşim karakterindeki değişiklikler sosyal, kültürel ve siyasi olaylarla yakından ve doğrudan ilişkilidir. Bu kentsel gelişim sürecini Şekil 3.1'de gösterildiği üzere Koç (2006) şu şekilde ele almaktadır. 1462 y1lı kentin kuruluşu, 1462 1700 yılları arası savunma ve garnizon kenti, 1700 - 1900 y1lları aras1 ticaret kenti, 1900 1950 yılları arası savaşlar ve yıkım, 1950 - 1960 yılları arasında ilk planlama dönemi, 1960 1970 yılları arasında büyüyen ve yükselen kent, 1980 - 1984 yılları arasında İmar Yasası değişikliğine göre kamu eliyle yapılaşma, 1984 - 2000 yılları rantsal gelişimin arttığı dönem olmuştur. 2004 ve sonrasında korumacı bir yaklaşım sergilenmiştir (Sağlık, 2014). Yerel Gündem 21 ve Çanakkale Kent Konseyi oluşumları, kenti sürdürülebilirlik kavramı ile tanıştırmıştır. Çanakkale Belediyesi ve kentin diğer aktörlerinin katılımı ile Kent Konseyi tarafından hazırlanan Kent Eylem Planı, imar planları ile birlikte bir stratejik plan olarak kente kazandırılmıştır (Anonim, 2018c). Yerel Gündem 21 ve Kent Konseyi'nin varlığı kentin geleceği için yapılan çalışmalarda önemli paydaşları oluşturmaktadır. Böylece kentin kimliğinin tanınması, korunması ve sürdürülebilirliğinin sağlanması için önemli bir yaklaşım sergilenmektedir. 


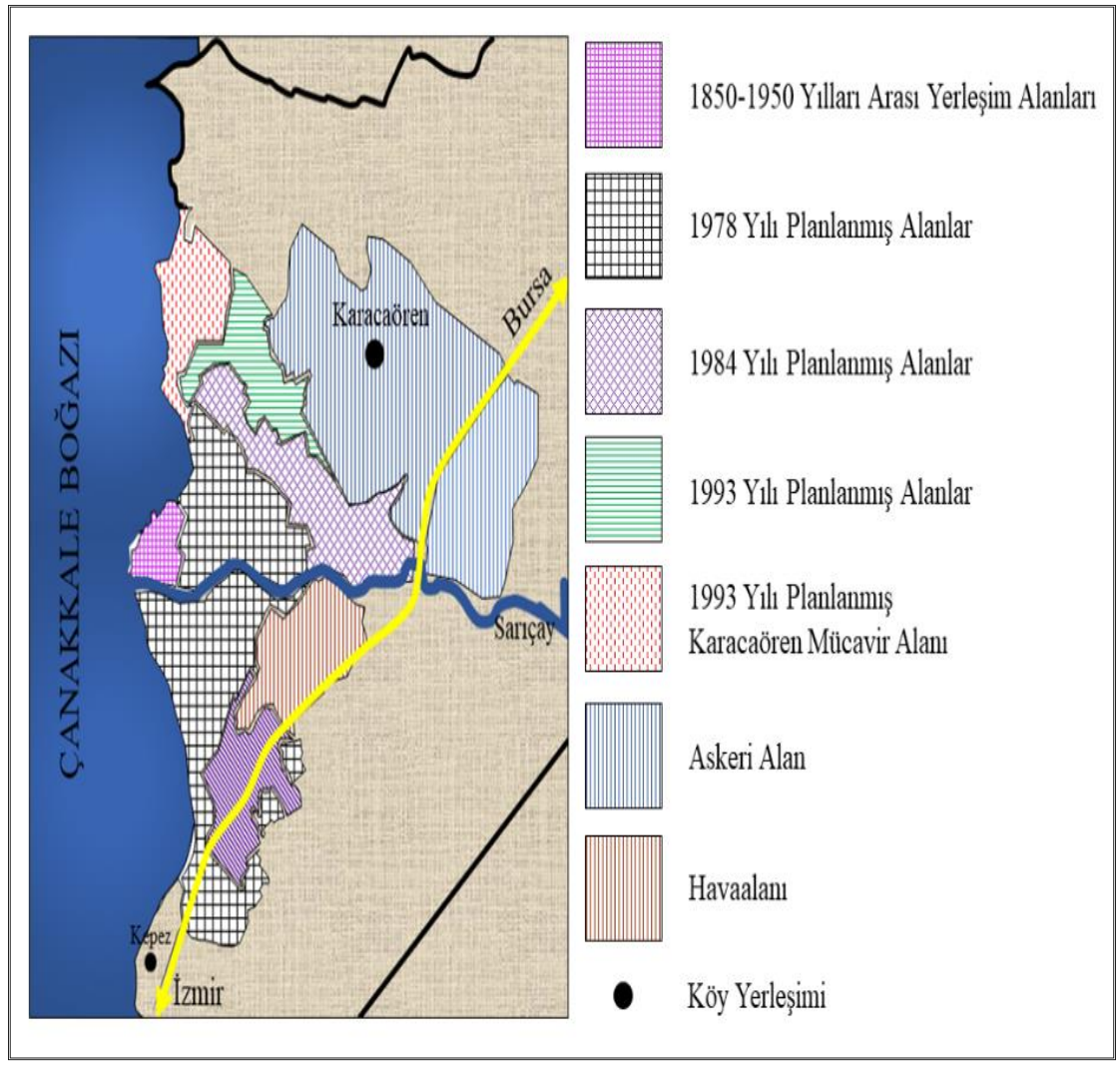

Şekil 3.1. Çanakkale Kentinin Kronolojik Gelişim Haritası (Koç, 2006)

\subsection{Anket Uygulaması Bulguları}

Kent kullanıcılarının yaşadıkları kenti kimliksel açıdan nasıl değerlendirdiği ve algıladığını anlamak amacıyla yöntem bölümünde de açıklandığı üzere, çalışma alanında 112 kişi ile bir anket görüşmesi yapılmıştır.

Ankete katılan kent kullanıcılarının demografik yapısı Çizelge 3.1'de gösterildiği gibidir. Rastlantısal örnekleme tekniği ile uygulanan ankete katılanların \%66.1'i kadın ve \%33.9'u erkektir. Ankete katılan kullanıcıların meslekleri incelendiğinde \%25.9'u kamu sektöründe, \%23.2'sinin özel sektörde çalıştığ1, \%50.9'unun öğrenci olduğu belirlenmiştir. Kent kullanıcılarının Çanakkale'de bulunma süreleri sorgulandığında \%49.1'i 0-5 yıl, \%14.3'ü 610 yıl, \%11.6'sı 11-15 yıl ve \%25'i 16 ve üstü yıl arasında yaşadıkları belirlenmiştir. Kentin uzun süreli misafirlerinin imgelerini ölçmek çalışmanın amacına ulaşmasını desteklemektedir.

Çizelge 3.1. Ankete katılan kent kullanıcılarının demografik yapısı

\begin{tabular}{|l|c|l|c|c|c|}
\hline Cinsiyet & Yüzde (\%) & Meslek & Yüzde (\%) & Çanakkale’de bulunma süreleri & Yüzde (\%) \\
\hline Kadın & 66.1 & Kamu & 25.9 & $0-5$ y1l & 49.1 \\
\hline Erkek & 33.9 & Özel sektör & 23.2 & $6-10$ y1l & 14.3 \\
\hline Toplam & 100 & Öğrenci & 50.9 & $11-15$ yıl & 11.6 \\
\hline & & Toplam & 100 & 16 ve üstü yıl & 25 \\
\hline & & & & Toplam & 100 \\
\hline
\end{tabular}

Kent kullanıcılarına göre Çanakkale kentini tanımlayan "Kimlik Tipi" tanımlaması için Tarih -Spor - Turizm -Ticaret - Sanayi - Savunma/Askeriye - Üniversite - Rüzgar - Kültür - Boğaz Deniz -Liman-Barış Kenti kavramları arasından en iyi tanımlayan ilk üç ifadenin sıralaması Çizelge 3.2' de yer almaktadır. Veriler doğrultusunda kent kullanıcılarının Çanakkale kenti 
için belirlediği 1. sırada kimlik tipi Tarih Kenti; 2. sırada kimlik tipi Turizm Kenti; 3. sırada kimlik tipi ise Boğaz Kenti şeklinde belirlenmiştir. Spor, sanayi, ticaret ve savunma kavramları hiç işaretlenmemiştir.

Çizelge 3.2. Çanakkale Kentini Tanımlayan "Kimlik Tipi" tanımlaması

\begin{tabular}{|c|c|c|}
\hline & Kimlik Tipi Tanımlama Sıralamas1 & Tanımlayıc1 Kavram \\
\hline \multirow{2}{*}{ Kentin Kimlik } & 1. sıra & Tarih kenti \\
\cline { 2 - 3 } Tipi Tanımlaması & 2. sıra & Turizm kenti \\
\cline { 2 - 3 } & 3.sıra & Boğaz kenti \\
\hline
\end{tabular}

Çanakkale kentinin kültürel ve ekonomik kimliğini yansıtan kavramların değerlendirilmesi Çizelge 3.3'te gösterildiği gibidir. Ankete katılan kent kullanıcıları Çanakkale kentinin kültürel değerini belirlemek için "Tarih- Turizm-Askeriye-Deniz Rüzgar-Tarım ÜrünleriBalıkçılık-Halk Oyunları-Yöresel Mutfak-Geleneksel El Sanatları-Diğer” kavramları arasından \%91.07 oranla Tarih kavramını seçmiştir. Çanakkale kentinin ekonomik kimliğini yansitan kavram nedir sorusuna verilen yanitlar doğrultusunda \%37.5 oranla Tarih olarak belirlenmiştir.

Çizelge 3.3. Çanakkale Kentinin kültürel ve ekonomik kimliğini yansıtan kavramlar

\begin{tabular}{|c|c|c|}
\hline Kimliği Yansıtan Kavramlar & Tanımlayan Kavram & A ğırlık (\%) \\
\hline Kültürel kimlik & Tarih & 91.07 \\
\hline Ekonomik kimlik & Tarih & 37.5 \\
\hline
\end{tabular}

Çanakkale kentini simgeleyen kentsel donatı, işaret ve yerleşim ölçeğinde simgeler Çizelge 3.4 'te gösterildiği gibi analiz edilmiştir. Ankete katılan kent kullanıcıları Çanakkale kentini simgeleyen kentsel donatı birimi olarak sırasıyla " rüzgâr gülleri-manolya ağacı-çeşme-oturma birimleri-otobüs duraklar1-zemin kaplamas1-bisiklet istasyonları" kavramları arasından \%42.85 oranla Rüzgar Güllerini seçmiştir. Ankete katılan kent kullanıcıları Çanakkale kentini simgeleyen kentsel işaret değeri nedir sorusu için" Truva Atı, Saat Kulesi, Nusret Mayın Gemisi, Aynalı Testi, Feribotlar, Sarıçay Köprüsü, Yatlar, Balık Tutan Kentliler, İnönü Köprüsü, Dur Yolcu" değerleri arasından \%19.64 oranla Saat Kulesi yapısal öğesini seçmişlerdir. Kent kullanıcılarına göre 'Çanakkale Kenti kimliğini simgeleyen yerleşim ölçeğinde aklınıza gelen ilk üç alan neresidir' sorusu yöneltilmiştir. Verdikleri yanıtlar doğrultusunda önceden belirlenmiş olan öneriler arasından \%60.71 oranla İskele Meydanı olarak belirlenmiştir.

Çizelge 3.4. Kimliği simgeleyen ölçekler için kullanılan kavramlar

\begin{tabular}{|l|l|l|}
\hline Kimliği simgeleyen ölçekler & Tanımlayan Kavram & Ağırlık (\%) \\
\hline Kentsel mobilya-donatı ölçeğinde kimlik & Rüzgar Gülleri & 42.85 \\
\hline İşaret ölçeğinde kimlik & Saat kulesi & 19.64 \\
\hline Yerleşim ölçeğinde kimlik & İskele Meydanı & 60.71 \\
\hline
\end{tabular}

Kent kullanıcılarının Çanakkale kenti için oluşturdukları imgeleri kabul etme dereceleri Çizelge 3.5'te yer aldığ gibidir. Kent kullanıcılarının Çanakkale için oluşturdukları imgelerini ölçmeye yönelik sorular sorulmuştur. Verilen yanıtlar doğrultusunda; \%44.6 oranla kentin bilişsel haritasını çizebileceği; \%43.8 oranla kenti eski bir fotoğraftan tanıyabileceği; $\% 50$ oranla kullanıcı için kentte mimari özellikleri olan yerler bulunduğu; \%46.4 oranla kullanıcı için kentte sosyal ve psikolojik açıdan anlamı olan yerler olduğu; \%87.5 oranla 
kentin kültürel yapısı, mimari özellikleri ve tarihi geçmişinin kullanıcılar için önem taşıdığı sonucuna ulaşılmıştır.

Çizelge 3.5. Kent kullanıcılarının Çanakkale için oluşturdukları imgeler

\begin{tabular}{|l|c|c|}
\hline Kent İmgesi & Kabul etme durumu & Ağırlı (\%) \\
\hline Kentin bilişsel haritasını çizebilme algısı & Kabul ediyorum & 44.6 \\
\hline Kenti eski bir fotoğraftan tanıabilme algısı & Kararsızım & 43.8 \\
\hline Kent mimari özellikleri olan yerlerin varlığ1 & Kabul ediyorum & 50 \\
\hline $\begin{array}{l}\text { Kentte sosyal ve psikolojik açıdan anlamlı yerlerin } \\
\text { varlığ1 }\end{array}$ & Kabul ediyorum & 46.4 \\
\hline $\begin{array}{l}\text { Kentin kültürel yapısı, mimari özellikleri ve tarihi } \\
\text { geçmişi önemsiz }\end{array}$ & $\begin{array}{c}\text { Kesinlikle kabul } \\
\text { etmiyorum }\end{array}$ & 87.5 \\
\hline
\end{tabular}

Kent kullanıcılarının Çanakkale'de simgesel yollar, kentin gelişimini engelleyen sınırlar, odaklar ve duyusal algı öğelerine ilişkin yaptıkları değerlendirmeler Çizelge 3.6'da verilmiştir. Ankete katılan kent kullanıcılarının Çanakkale'de en sık kullandıkları ulaşım aksları sorulmuştur. Verilen yanıtlar içerisinde Atatürk Caddesi \%32.5 gibi büyük bir farkla ilk sırada yer alırken; Demircioğlu caddesi \%14.3, İnönü Caddesi \%13.4 oranlarıyla takip eden caddeler olarak belirlenmiştir. Ankete katılan kent kullanıcılarına Çanakkale kentinde mekânsal bölünmelere neden olan engeller sorulmuştur. Verilen yanıtlar içerisinde Sarıçay \%53.6 gibi büyük bir farkla ilk sırada yer alırken; Troya Caddesi (\%8) ve Havaalanı (\%15.4) kenti bölen veya sınırlayan diğer engeller olarak belirlenmiştir (Çizelge 3.6). Ankete katılan kent kullanıcıları Çanakkale kentinde toplanma, meydan ve kavşak niteliğindeki alanlar Cumhuriyet Meydanı (\%29.5), İskele Meydanı (\%15.2) ve Saat Kulesi Meydanı (\%9.8) olarak değerlendirilmiştir. Ankete katılan kent kullanıcıları Çanakkale kentinde görsel, işitsel, koku gibi duyulara hitap eden algı öğeleri sorgulanmıştır. Verilen yanıtlara göre; görsel alg1 öğesi olarak: Truva Atı (\%29.5), panoramik boğaz manzarası (\%15.2) koku alg1 öğesi ise deniz kokusu (\%9.8) olarak ifade edilmiştir.

Çizelge 3.6. Kent kullanıcıları tarafından Çanakkale'ye ilişkin öğelerin değerlendirilmesi

\begin{tabular}{|c|c|c|c|}
\hline & Tanımlanan Değerler & Siralama & Yüzde (\%) \\
\hline \multirow{3}{*}{$\frac{\vec{z}}{\overline{0}}$} & Atatürk Caddesi & 1,00 & 32,5 \\
\hline & Demircioğlu Caddesi & 2,00 & 13,4 \\
\hline & İnönü Caddesi & 3,00 & 14,3 \\
\hline \multirow{3}{*}{ 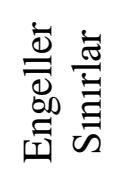 } & Sarıçay & 1,00 & 53.6 \\
\hline & Troya Caddesi & 2,00 & 8 \\
\hline & Havaalanı & 3,00 & 13.4 \\
\hline \multirow{3}{*}{$\frac{\frac{\hbar}{\frac{\pi}{\pi}}}{\frac{\pi}{0}}$} & Cumhuriyet Meydanı & 1,00 & 29.5 \\
\hline & İskele Meydanı & 2,00 & 15.2 \\
\hline & Saat Kulesi Meydanı & 3,00 & 9.8 \\
\hline \multirow{3}{*}{ 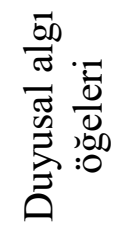 } & Truva Atı & 1,00 & 29.5 \\
\hline & Boğaz Panoramik Manzara & 2,00 & 15.2 \\
\hline & Deniz Kokusu & 3,00 & 9.8 \\
\hline
\end{tabular}




\section{Sonuç}

Kullanıcı algısına yönelik kentsel kimlik analizini konu alan bu çalışmada araştırma alanı olarak Çanakkale kent merkezi seçilmiştir. Daha önceki bölümde vurgulandığı üzere bu alanın seçilmesinde, kentin geçmişten günümüze kentsel kimliği yansıttığı düşünülen bileşenleri taşıması önemli faktör olmuştur. Kentin sahip olduğu farklı katmanların 1şı̆̆ında kimliğinin ortaya çıkarılması ve sürekliliğinin sağlanabilmesi için kayıt altına alınması gerekliliği düşünülmektedir. Nüfusu yaklaşı 132 bin olan Çanakkale; zengin doğal, kültürel, tarihi ve çevresel değerler ile evrensel bir öneme sahip kıyı ve boğaz kentidir.

Aslanoğlu (2000) çalışmasında Bursa'ya ilişkin kentsel kimlik tespitinde tarihi sürecin etkili olduğunu belirtmiştir. Şahin (2011) yaptığı çalışmada; Eskişehir'i ise, coğrafi konum nedeniyle kente gelen muhacirlerin yerleşimlerinden dolayı göçmen kenti olarak tanımlamıştır. Kentsel kimliğin bileşenlerinden olan yollar; kentin günlük hayatında en çok kullanılan güzergahlardır. Lynch (2015), yapmış olduğu çalışmada; Boston için Tremont Caddesi, Jersey City için Hudson Bulvarına ulaşan yollar; Los Angeles için otoyollar olarak belirlemiştir. Bu çalışma ile Çanakkale kentinin kavramsal yapısının tarih, turizm ve boğaz kompozisyonundan oluştuğunu ortaya koymaktadır. Çanakkale kentinin kimlik bileşeni olarak yer alan yollar ise; Atatürk Caddesi, Troya Caddesi ve İnönü Caddesi olarak kimlik kartında yer almaktadir.

Kent içerisinde yollar kadar etkili olmayıp kolay algılanmayan ancak sürekliliği hissedilen kimlik bileşeni kenar/sınır engel öğeleridir. Bu kapsamda Lynch (2015)'in çalışmasında; Boston kentinde yer alan Charles Nehri'ni en büyük kenar olarak tanımlamıştır. Çanakkale kentinde yapılan bu çalışma ile Boston kentine ilişkin tespiti benzerlik göstermektedir. Çanakkale kentinin sahip olduğu kıyı uzunluğu ve boğazın varlığı kentsel kenar/sınır niteliği taşımaktadır.

Kentlinin günlük hayatında kullandığı, çeşitli etkinlikler için bir araya geldiği; önemli yolların kesişerek yoğun kullanımların olduğu alanlar kentsel kimlikte odaklar olarak tanımlanmaktadır. Lynch (2015) çalışmasında; Boston'da Scolloy Meydanı, Los Angeles'ta Pershing Meydanı'nı kentsel odak olarak tespit etmiştir. Bu çalışmaya benzer olarak Çanakkale kenti için kentsel odaklar Cumhuriyet Meydanı, Saat Kulesi Meydanı ve İskele Meydanı olarak sıralanmaktadır. Bu kentsel odaklar aynı zamanda kent kullanıcısı tarafindan yerleşim ölçeğinde bölgeler olarak tanımlanmaktadır.

Kentsel donatı ve işaret ögeleri kentin siluetinde yer alan ve kentsel alanda referans noktalar niteliğindeki yapısal değerlerdir. Lynch (2015) çalışmasında; Los Angeles'ta belediye binasına ait olan yapının çatı bölümü kentte işaret ögesi olarak tanımlanmıştır. Çanakkale kentinin kentsel donatı ve işaret ögeleri ise; rüzgar gülleri ve Saat Kulesi olduğu bu çalışma ile tespit edilmiş olmaktadır.

Bir kentin kimliğini analiz ederken kentin alanlarının içine girmek orada bulunmak gerekmektedir. Bu nedenle çalışma alanına yönelik kent kullanıcılarına uygulanan anketler ile çalışma desteklenmiştir. Bu süreçte kentliler, günlük yaşamın yoğun temposu içinde çalışmamıza kentlilik bilinci çerçevesinde gönüllü olarak zaman ayırmışlardır. Kent kimliği kavramı güçlendikçe kent kullanıcıları için o kenti benimsemek ve sahiplenmek daha anlamlı olmaktadır. Kent kullanıcılarının uzun ya da kısa süreli kentte bulunma durumları değişkenlik göstermesine karşın kente yönelik oluşan imgeler ortak bir tablo çizmektedir. Çalışma 
kapsamında belirlenen yöntem ile Çanakkale kentine ait kentsel kimlik bileşenleri tespit edilmiş olup Çanakkale kentsel kimlik kartı oluşturulmuştur (Çizelge 4.1).

Çizelge 4. 1. Çanakkale kentsel kimlik kartı

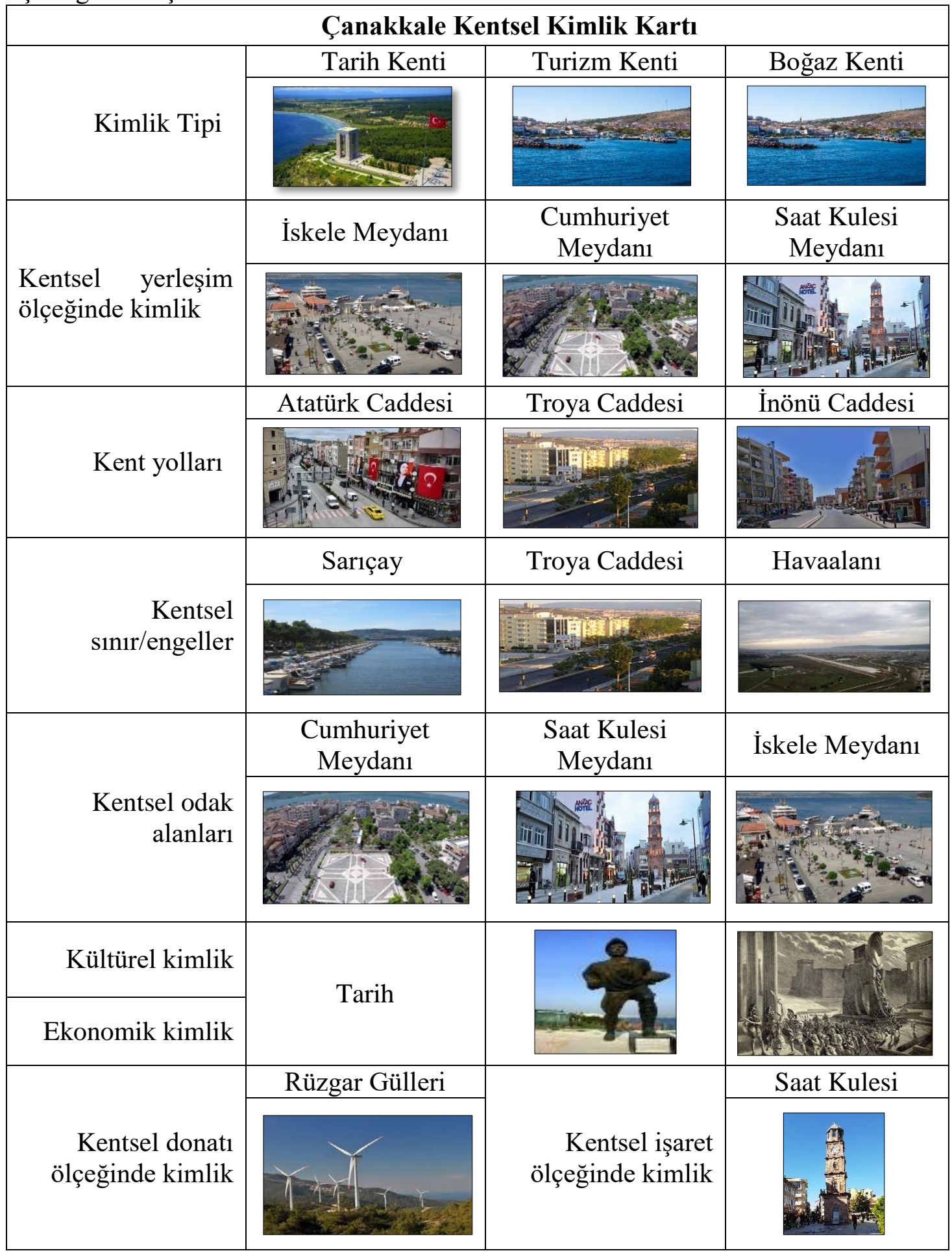

Kentsel kimlik bileşenlerini tanımak, korumak ve geliştirmek için gereken duyarlılık ortaya çıkmaktadır. Kentin geleceği için yapılan çalışmalarda kimlik bileşenlerinin kent günlügüne yansıtıldığı bir tasarım dili oluşturulmalıdır. Kentte yaşamak olgusu yerine kenti yaşamak ancak kimlikli kentlerde mümkün olmaktadır. Bu nedenle;

- Kentlerin planlanmasında tek tip kent olma kaygısının önüne geçmek 
- Mekânlara anlam kazandırmak, kentin sahip olduğu kimliği korumak,

- Kentin kavramsal yapısını destekleyen, kentin kimlik bileşenleri ile bütünleşen çalışmalar yapmak

- Kentin özgünlüğünü koruyarak tarihsel ve kültürel değerlerini mekânlara ve kentin günlüğüne yansitmak,

- Tarih ve kültürel değerlerin sürdürülebilir olmasını sağlamak

- Kentlerin okunabilirliğini ve kentsel mekanların erişilebilirliğini kolaylaştırmak

- Doğal ortam verilerinin analiz etmek ve kentsel tasarıma entegre edilmiş çalışmalar yapmak

- Kenti tanımaya yardımcı olan, kentsel yaşamın geçtiği ve toplumun sosyalleşmesine olanak veren alanlarda tasarımlar yapmak; bu alanlarda sosyo-kültürel refereans noktaları oluşturan işaret ögelerini kaliteli tasarım yaklaşımları ile ön plana çıkarmak,

- Kentin doğal ve çekici panoramik görsel etki değerini kentli için ulaşılabilir kılan tasarım yaklaşımları sergilemek gerekmektedir. 


\section{Kaynakça}

Anonim, 2014. Çanakkale Kent Rehberi. Çanakkale Belediyesi Kültür Hizmeti.

Anonim, 2018a. Oxford Dictionary. https://en.oxforddictionaries.com/definition/identity Erişim Tarihi: 17.11.2018

Anonim, 2018b. Çanakkale Rehberi. T.C. Çanakkale Valiliği. http://www.canakkale.gov.tr/tr

Anonim, 2018c. Çanakkale Kent Konseyi. http://www.canakkalekentkonseyi.org/kentkonseyi-tanitim-vizyon-misyon/

Aslanoğlu R.A., 2000. Kent, Kimlik Ve Küreselleşme (2. Bask1). Ezgi Kitabevi, Bursa.

Calvino I., 1972. Görünmez Kentler. Yap1 Kredi Yayınları. 19. Bask1; Syf:40.

Cohen J., 1988. Statistical Power Analysis For The Behavioral Sciences. Hillsdale, NJ: L.

Çöl Ş., 1998. Kentlerimizde Kimlik Sorunu Ve Günümüz Kentlerinin Kimlik Derecesini Ölçmek İçin Bir Yöntem Önerisi. Doktora Tezi. Mimar Sinan Üniversitesi Fen Bilimleri Enstitüsü, İstanbul.

Google Images, (17.11.2018). Architecture of the City.

http://mirandasurbandesignseminarcourse.blogspot.com/2016/10/module-3-influentialurban-design.html

Koç T., 2006. Çanakkale’nin Kentsel Gelişimi (1462-2006) İle Fiziki Coğrafya İlişkisi. Çanakkale Kent Konseyi Yayınları Kitap Dizisi, Yayın No: 2, Çanakkale.

Kodal G., 2014. Atapark Ve Tabakhane Köprüsü Arasındaki Tarihi Aksın Kent Kimlik Bileşenleri Açısından Değerlendirilmesi. Yüksek Lisans Tezi. Karadeniz Teknik Üniversitesi Fen Bilimleri Enstitüsü, Trabzon.

Lynch K., 2015. The Image of The City, (2. Bas.). Türkiye İş Bankası Kültür Yayınları.

Mansour H., 2015. The Lost Identity of The City: The case of Damascus. CITTA 8 th Annual Conference on Planning Research AESOP TG Public Spaces \& Urban Cultures Event.

Oğurlu İ., 2014. Çevre - Kent İmajı - Kent Kimliği - Kent Kültürü Etkileşimlerine Bir Bakış. İstanbul Ticaret Üniversitesi Fen Bilimleri Dergisi, 13(26): 275-293. 
Okumuş G., 2011. Sürdürülebilir Kentsel Yenileme İçin Bir Yaklaşım: Çanakkale Fevzipaşa Mahallesi Örneği. Yüksek Lisans Tezi. İstanbul Teknik Üniversitesi Fen Bilimleri Enstitüsü, İstanbul.

Özgür Ş., 2011. Akdeniz Kentlerinin Karakteristik Özelliklerinin Peyzaj Mimarlığı Açısından İrdelenmesi: Antalya Örneği. Yüksek Lisans Tezi. Ankara Üniversitesi Fen Bilimleri Enstitüsü, Ankara.

Pazhuhan M., Zayyarı K., Ghasemzadeh B., Qurbanı H., 2015. Urban Identity And Iranian New Towns. Journal of Urban and Regional Analysis, VII (1): 83 - 100.

Prajapati B., Dunne M., Armstrong R., 2010. Sample Size Estimation And Statistical Power Analyses. Optometry Today, 7:1-9.

Rıza M., Doratli N., Fasli M., 2012. City Branding and Identity. Procedia - Social and Behavioral Sciences, 35: 293 - 300.

Sağlık A., 2014. Çanakkale Kenti Rekreasyon Potansiyelinin Kentlerin Yaşanabilirliği Açısından Değerlendirilmesi. Doktora Tezi. Çanakkale Onsekiz Mart Üniversitesi Sosyal Bilimler Enstitüsü, Çanakkale.

Soydan S., 1997. Çanakkale Kent Kimliği TMMOB Harita Ve Kadastro Mühendisleri Odası, Haber Bülteni Sayı:36, İstanbul.

Şahin C., 2011. Bir Göçmen Kenti Olarak Eskişehir Ve Eskişehir'in Sosyo-Kültürel Yapısında Tatar Kimliği. İdeal Kent, Kent Araştırmaları Dergisi 3: 220-242.

Tavakoli N., 2010. The Role Of Physical Identity Of City In Urban Sustainability (The Case Study: Yazd, Iran). 14 Th International Planning History Society Conference.

TDK, 2018. (15.11.2018). Güncel Türkçe Sözlük, 2018. T.C. Başbakanlık Atatürk Kültür Dil Ve Tarih Yüksek Kurumu Türk Dil Kurumu. http://www.tdk.gov.tr/index.php?option=com_gts\&view=gts Erişim Tarihi: 17.11.2018

Tombul M., 2015. Çanakkale Kültür Envanteri, Arkeolojik Yerleşim Alanları Ve Sanat Tarihi Yapıları. Çanakkale Valiliği.

Topçu K., 2011. Kent kimliği üzerine bir araştırma: Konya örneği. Uluslararası İnsan Bilimleri Dergisi 8:2. 
TÜİK, 2018. (15.11.2018). Türkiye İstatistik Kurumu, Adrese Dayalı Nüfus Kayıt Sistemi. http://www.tuik.gov.tr/UstMenu.do?metod=temelist

Uçkaç L., 2006. Kentsel Tasarımın Kent Kimliği Üzerine Etkileri: Keçiören Örneği. Yüksek Lisans Tezi. Ankara Üniversitesi, Fen Bilimleri Enstitüsü, Ankara.

Zhou B., Liu L., Oliva A., Torralba A., 2014. Recognizing City Identity via Attribute Analysis of Geo-Tagged Images. Lecture Notes In Computer Science, Vol 8691. 